\title{
Evaluation of seismic attributes for reservoir characterization over Edi field, Niger delta, Nigeria using 3d seismic data
}

\author{
Nyeneime O. Etuk ${ }^{1 *}$, Mfoniso U. Aka ${ }^{2}$, Okechukwu E. Agbasi ${ }^{3} *$, Johnson C. Ibuot ${ }^{2}$ \\ ${ }^{1}$ Department of Physics, University of Uyo, Uyo \\ ${ }^{2}$ Department of Physics and Astronomy, University of Nigeria, Nsukka \\ ${ }^{3}$ Department of Physics, Federal University of Agriculture, Umudike \\ *Corresponding author E-mail: agbasi.okechukwu@gmail.com
}

\begin{abstract}
Seismic attributes were evaluated over Edi field, offshore Western Niger Delta, Nigeria, via 3D seismic data. Manual mappings of the horizons and faults on the in-lines and cross-lines of the seismic sections were done. Various attributes were calculated and out put on four horizons corresponding to the well markers at different formations within the well were identified. The four horizons identified, which includes: H1, H2, H3 and H4 were mapped and interpreted across the field. The operational agenda was thru picking given faults segments on the in-line of seismic volume. A total of five faults coded as F1, F2, F3, F4 and F5, F1 and F5 were the major fault and were observed as extending through the field. Structural and horizon mappings were used to generate time structure maps. The maps showed the various positions and orientations of the faults. Different attributes which include: root mean square amplitude, instantaneous phase, gradient magnitude and chaos were run on the 3D seismic data. The amplitude and incline magnitude maps indicate direct hydrocarbon on the horizon maps; this is very important in the drilling of wells because it shows areas where hydrocarbons are present in the subsurface. The seismic attributes revealed information, which was not readily apparent in the raw seismic data.
\end{abstract}

Keywords: Acoustic Impedance; Direct Hydrocarbon Indicator; Faults; Horizons; Time Slice.

\section{Introduction}

In most exploration and reservoir surveys, structural imaging and assuming amplitudes of reflections are their main objectives. Seismic attributes are desirable for 3D seismic data set (Tanner et al., 1979) for characterizing oil and gas reserves. This is based on the precise information derived from seismic attributes, which are dominant aid for a better geological and geophysical interpretation of data, which lessen the exploration menaces of drilling very expensive wells. Initiation of 3D seismic know-how and influential workstation computers have made it conceivable to excerpt accurate information from the character of the seismic waveform for the cohort of numerous attributes (Babangida et al., 2013). Seismic attributes, offers a rapid way of envisaging the inclinations of faults and fractures, predominantly those outside seismic resolution that are significant in reservoir engineering. Profusion evidence on fault size and geometry will aid in delineation of suitable well locations (Taner 2001), which is vital for estimation of elementary seismic measurements, which comprises: time, amplitude, frequency and attenuation that makeup basis seismic attributes sorting and gives more insight to information not relived by seismic data (Brown, 2004; Sheriff, 1980; Chambers and Yarus, 2002). Seismic attributes are classified into two, which include: Geometrical attributes and Physical attributes (Sheriff, 1991). Physical attributes are those attributes which relates proportionally to wave propagation, lithology and supplementary constraints. It entails of the physical constraints of the subsurface which comprises: amplitude, phase and frequency. These can also be classified as pre-stack and post-stack attributes, and further classified as: instantaneous and wavelets attributes respectively. Instantaneous attributes are calculated sample, which indicates an incessant change of attributes to the time and space axis while the wavelet attributes signify features of wavelet and their amplitude variety (Schlumberger, 2009). Geometric attributes improve geometrical features of the input data. It is calculated from replication conformation and continuousness properties of the subsurface which includes: dip, azimuth and continuity. The most widely used and simplest seismic attribute is the amplitude, in many cases, amplitude relate sturdily by porosity and liquid saturation. Because, reservoir properties have a sturdy consequence on both velocity and density in which the seismic reflections are generated at margins where acoustic impedance changes in hydrocarbons and non- hydrocarbon's lithology (Pennington, 2001). In this research work, a number of seismic attributes were calculated and output of four horizons: H1, H2, H3 and H4 were mapped and interpreted with five faults coded as F1, F2, F3, F4 and F5 at different formations within the area. The intention of this research is to evaluate the seismic attributes of Edi field using petrel software and conduct seismic attribute's extraction from horizon maps for hydrocarbon exploration, which provide information on the fault and horizon's networks. 


\section{Geology of the study area}

Offshore Western Niger Delta, Nigeria is the area in study, is at latitudes $4^{\circ} 00^{1}$ and $6^{\circ} 00^{1} \mathrm{~N}$ and longitudes $3^{\circ} 00^{1}$ and $9^{\circ} 00^{1} \mathrm{E}$ as shown in Figure 1 (Obaje, 2013). "The Niger Delta is amongst the furthermost productive hydrocarbon provinces in the world. It has a degenerating clastic sequence extending 10-12 km wide, including a shelf, broad slope area and basin floor. It lies on a thick prism of clastic sediments, which forms the prominent seaward bulge in the continental margin off southern Nigeria" according to Damuth, (1994)]. "It is flanked on the northwest by a thick outcrop of uppermost cretaceous sedimentary rocks, which in turn the rest unconformable on extensive Precambrian basement complex" according to Ajisafe and Ako, (2013).

The tertiary Niger Delta is separated into stratigraphically formations namely: Akata, Agbada and Benin formations (Evamy et al., 1978). "Akata Formation at the base of the delta is predominately under-compacted and over-pressured sequence of thick marine shale, clays and siltstones with turbidities' sandstones. The formation is up to $7 \mathrm{Km}$ thick" according to Doust and Omatsola, (1990). "The major petroleum bearing units is the Agbada formation, about $3.7 \mathrm{Km}$ thick. It is also interchange categorization of paralic sandstones and shale stone" according to Etu-Efeotor, (1997). "Benin formation superimposing Agbada formation comprises of massive, uncoarse continental sandstones, and is about $0.28 \mathrm{~km}$ thick and $2.1 \mathrm{Km}$ in the region of maximum subsidence" according to Whiteman, (1982).

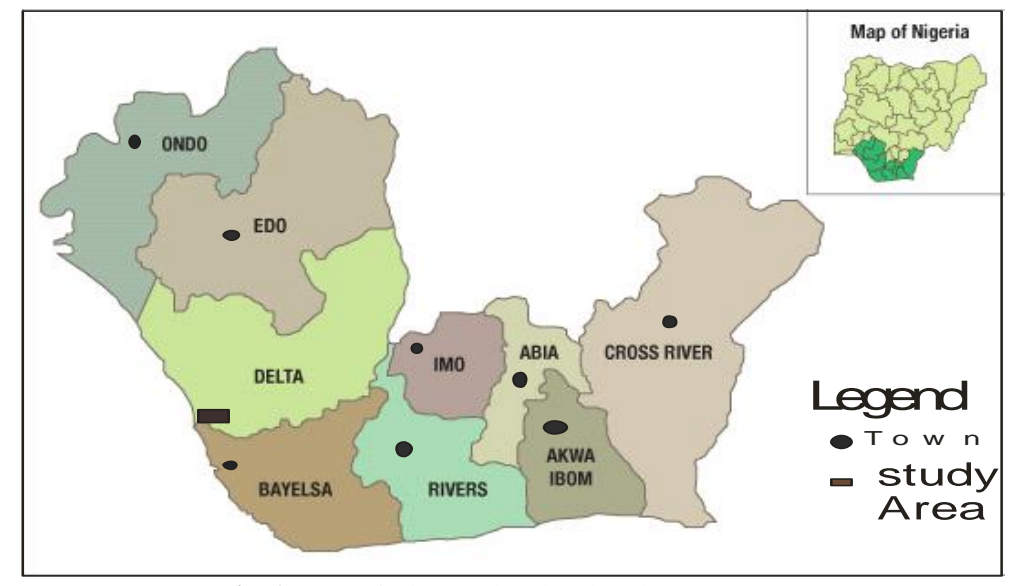

Fig. 1: Map of Niger Delta Showing the Study Area.

\section{Materials and methods}

3D seismic dataset was collected from Chevron Texaco Nigeria Limited. The seismic attribute analysis was carried out using the interactive petrel ${ }^{\mathrm{TM}}$ workstation. Petrel software was used to infer the seismic data and to create maps. The in-lines range from 5,800 to 6,200 $\mathrm{m}$ and the cross-lines range from 1,480 to $1,700 \mathrm{~m}$ with a total area of $71.33 \mathrm{~km}^{2}$ and the line space of $25 \mathrm{~m}$ respectively. The 3D seismic volume data was in SEG-Y format. In data analysis, the following steps were taken, which includes: Horizon mapping, fault picking and seismic attribute's generation. Horizons mapping on the inlines and crosslines namely: $\mathrm{H}_{1}, \mathrm{H}_{2}, \mathrm{H}_{3}$ and $\mathrm{H}_{4}$ were mapped through all the seismic sections. This was picked based on direct hydrocarbon indicator (DHI) and tracked using the 3D seeded auto- tracking functions. Furthermore, manual tracking function was used in some areas where auto-tracking could not track the events and time structure maps were produced from horizons. The second step was the fault picking, to generate the surfaces for each of the tracked horizons respectively. Five faults namely: $F_{1}, F_{2}, F_{3}, F_{4}$ and $F_{5}$ were identified. Faults which are displacement of rocks were easily identified and picked on the inlines of the seismic sections by selecting across points where the seismic events truncate or at points of continuity. These horizons correspond to well markers at different well formations as shown in Figure 2 and Figure 3. A number of various attributes were generated from seismic reflection, which includes: Root mean square amplitude, Instantaneous phase, gradient magnitude attribute and chaos attributes. Appropriate color scheme was chosen for each attribute and attribute maps were generated. These were done for proper geologic feature's interpretation of structure and stratigraphy, to unravel complex field subsurface structure and gain more insight into the complexities of the hydrocarbon hosting units within and outside Edi field.

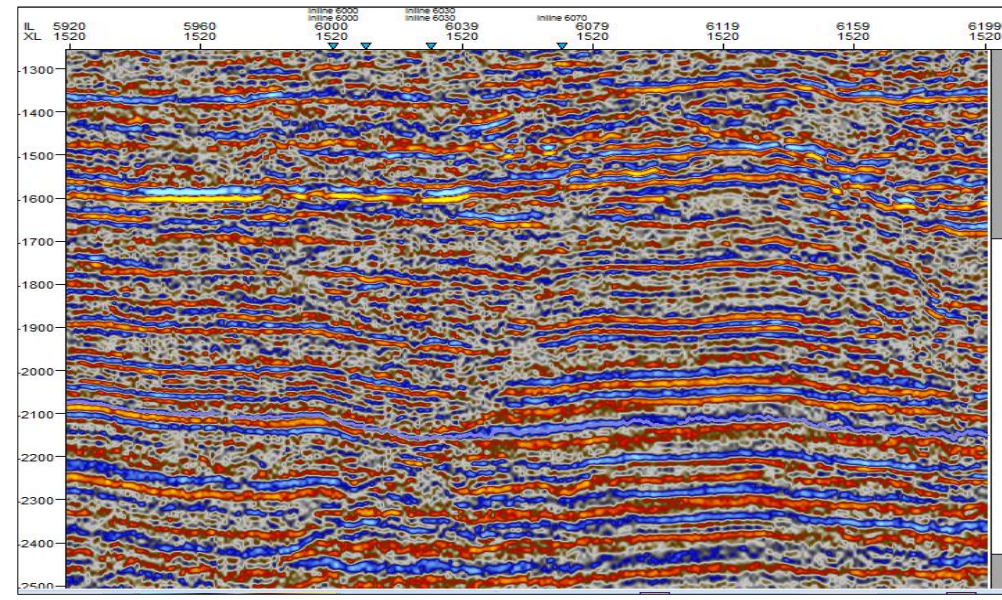

Fig. 2: Time Slice before Mapping. 


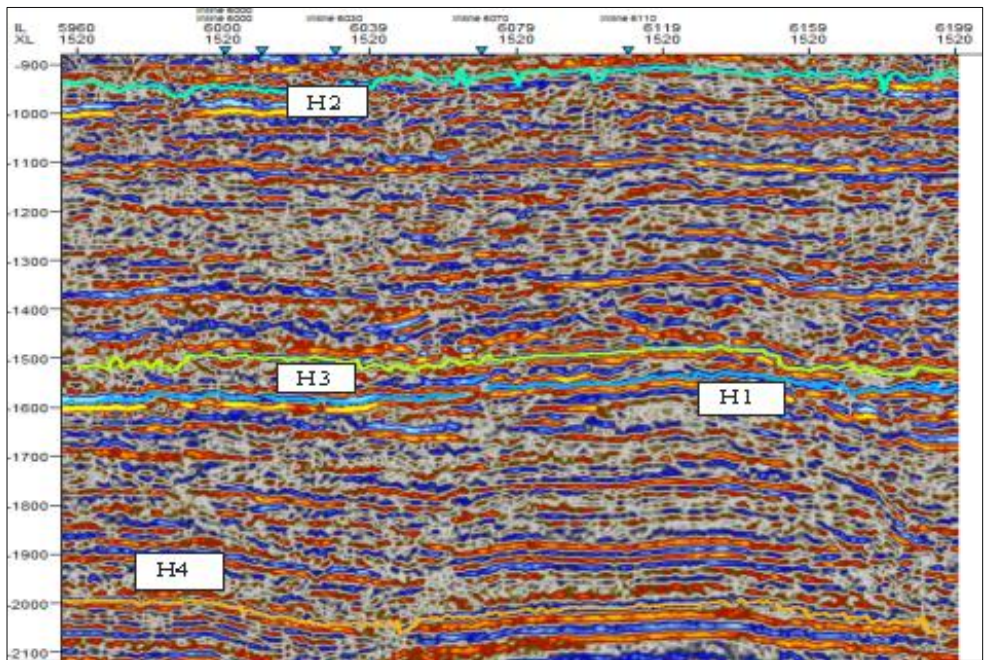

Fig. 3: Time Slice Mapped Horizons: $\mathrm{H}_{1}, \mathrm{H}_{2}, \mathrm{H}_{3}$ And $\mathrm{H} 4$ on the Interpretation Window.

\section{Results and discussion}

A total of four horizon maps namely: $\mathrm{H}_{1}, \mathrm{H}_{2}, \mathrm{H}_{3}$ and $\mathrm{H}_{4}$ were interpreted across the field. Horizon maps were generated using the mapped horizons. These horizons were marked to aid the construction of time surface maps so that various lithologies of the area with direct hydrocarbon indicators could be identified and analyzed appropriately. The maps generated revealed five faults namely: $F_{1}, F_{2}, F_{3}, F_{4}$ and $F_{5}$ in which two faults: $F_{1}$ and $F_{3}$ were identified as major growth faults and $F_{2}, F_{4}$ and $F_{5}$ were the minor faults that extend throughout the map as shown in Figure 5 respectively. Mapping Horizon, $\mathrm{H}_{1}$ and $\mathrm{H}_{3}$ form the middle slice, these corresponded to the formation offset of normal listric faults in the region identified by vertical section as shown in Figure 3. The root mean square amplitude attribute on the horizons delineates five major faults. These fault's trend from East to West with a throw from North to South which is clearly captured at the time structural map as shown in Figure 5.

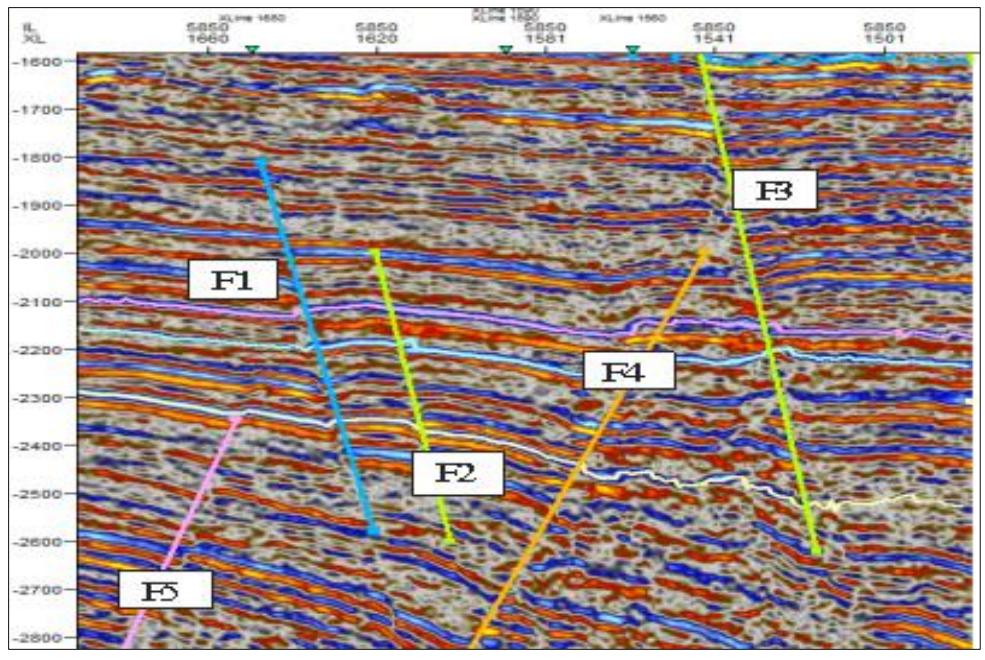

Fig. 4: Time Slice Faults: $F_{1}, F_{2}, F_{3}, F_{4}$ And $F_{5}$ on the Interpretation Window.

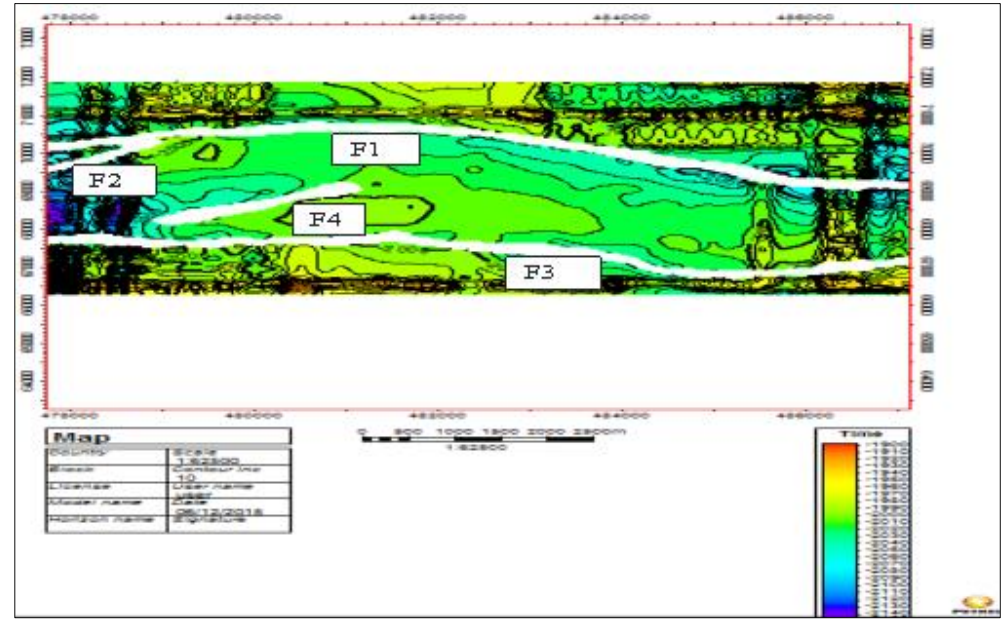

Fig. 5: Time Structure Map with Faults. 


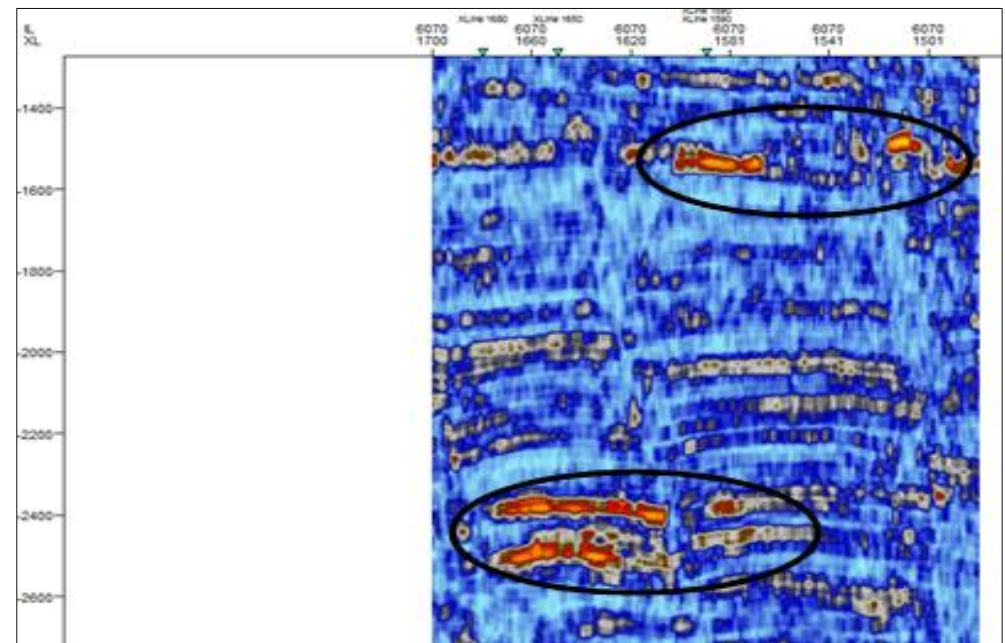

Fig. 6: Root Mean Square (RMS) Amplitude with Direct Hydrocarbon Indicator (DHI) Circled in the Figure.

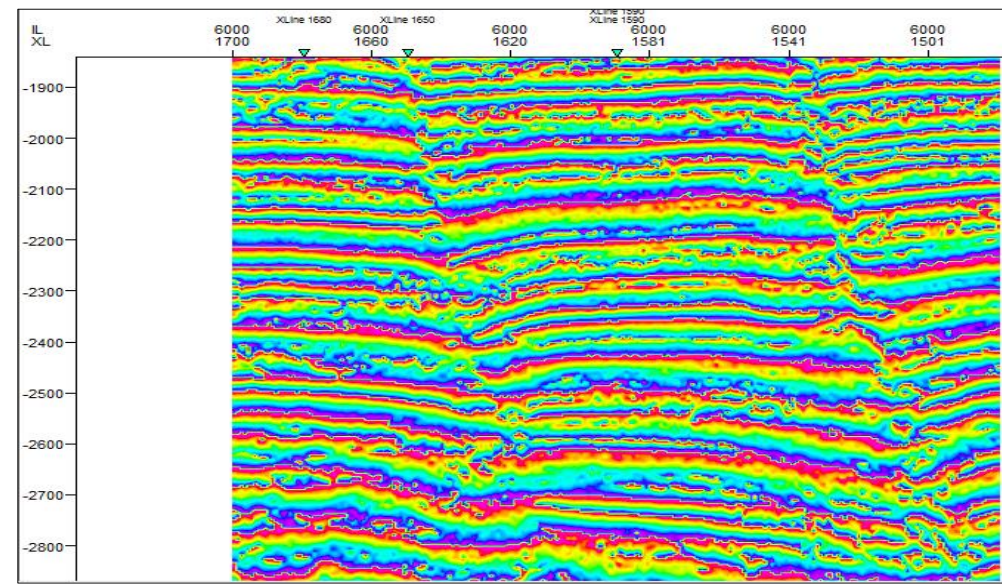

Fig. 7: Instantaneous Phase

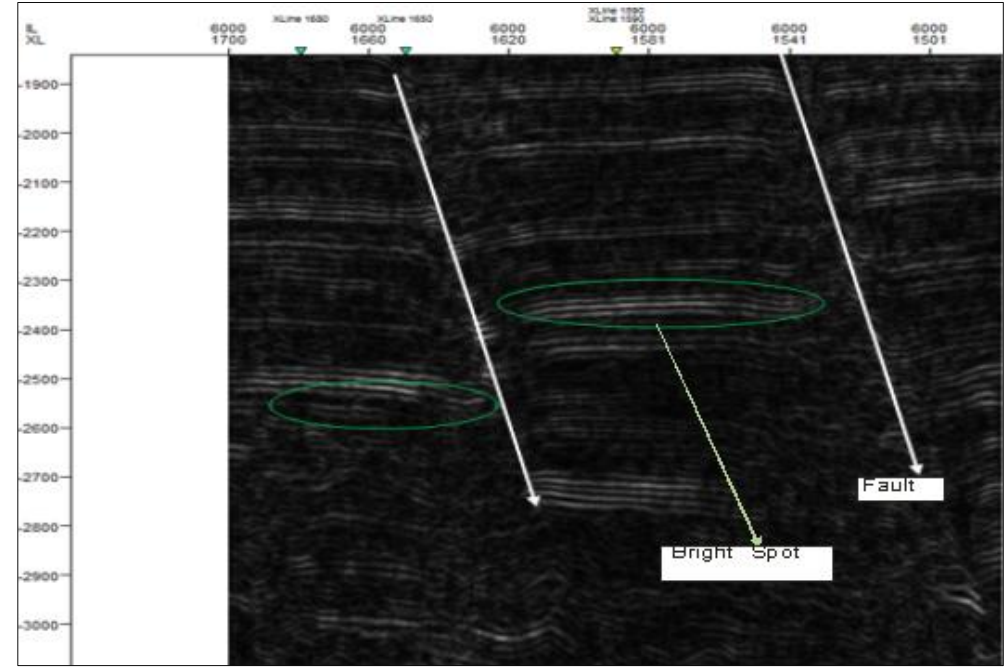

Fig. 8: Gradient Magnitude Attribute. 


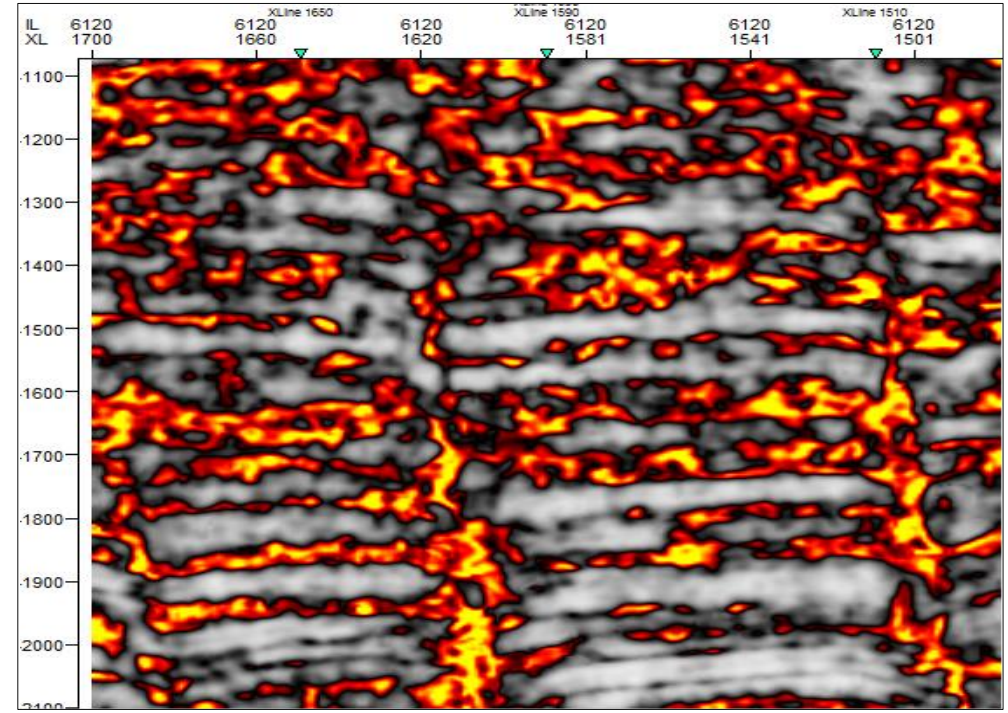

Fig. 9: Chaos Attribute.

These depict intermeddled coarse formations of clastic sediments, siltstones, clay and shale. Mapping horizon, $\mathrm{H}_{2}$ forms the upper slice formation with a large amount of sediments in the map, which shows the continuity of the reflection events, enhances faults and bedding of well as shown in Figure 7. These instantaneous phases improved reflectors continuity, enhances strong and weak events and visual appearances of faults. Mapping horizon, $\mathrm{H}_{4}$, from the lower formation with low values of frequency attributes toward the eastern horizon as shown in Figure 3. This is because the offset of faults formed within the lower formation, have not been filled with materials whose acoustic impedance is high such as shale. It is also, delineates by high degree of lateral continuity and parallel reflectors, which is clearly captured in Figure 9. These amplitudes of reflection connect strongly with porosity and liquid saturation of underlying formation (Oil, water and gas). Because reservoir properties have robust consequence on seismic reflection's generation, especially where the acoustic impedance changes [9]. On the other hand, the main reflectors interpreted across the entire field represent a well marker. This is delineated by high amplitude anomaly known as bright spots, which indicates the presence of hydrocarbon as shown in Figure 8. However, other nonhydrocarbon changes in lithology as a result of large amplitude reflections that delineate major and minor faults in the area. This shows that the area is highly faulted in all the four horizons, which depict a typical tectonic setting of the Niger Delta.

\section{Conclusion}

Outline of 3D visualization procedures of seismic attributes has produced better imaging of the structural and stratigraphic features of the seismic data set. It is worldwide to note that, an extensive variety of seismic attribute's permits a methodical classification and approaches to delineate the fault's network in the horizons. In this research, four horizons were picked across the in-lines and the cross-lines in which five faults were delineated and mapped, which reveals that the area is highly faulted that depicts the tectonic location of Niger Delta. Time structural maps of the surfaces were also produced to study the geometry of the structure harboring oil and gas in the field. Attribute maps such as RMS amplitude, instantaneous phase, gradient magnitude and Chaos were extracted to complement the structural maps. In addition, lower formation frequency attributes trends toward the eastern region of the horizons delineated by high amplitude anomaly of bright spots, which indicates the presence of hydrocarbon.

\section{References}

[1] Taner, M.T. Koehler, F. \& Sheriff, R.E. (1979). Complex Seismic Trace Analysis. Geophysics 44 (6): 1041. https://doi.org/10.1190/1.1440994.

[2] Babangida, W.J. Tim, J.R. \& Graham, K.W. (2013). Application of volumetric seismic discontinuity attribute for fault detection: Case study using deep water Niger Delta 3D seismic data. The Leading Edge, 32: 424-428. https://doi.org/10.1190/tle32040424.1.

[3] Taner, M.T. (2001). Seismic Attributes. Canadian Society of Exploration Geophysics Recorder. 26(9): 48-56.

[4] Brown, A.R. (2004). Interpretation of three-dimensional seismic data. American Association of Petroleum Geologists Memoir. $42(9)$ : 12-89.

[5] Sheriff, R.E. (1980). Seismic Stratigraphy. International Human Resources Development Corporation (IHRDC), Boston, p.227 https://doi.org/10.1007/978-94-011-6395-8.

[6] Chambers, R.L. \& Yarus, J.M. (2002). Quantitative use of seismic attributes for reservoir characterization CSEG Recorder. 14-15.

[7] Sheriff, R.E. (1991). Encyclopedic Dictionary of Exploration Geophysics. SEG.

[8] Schlumberger, (2009). Geological significance of seismic attribute. http://www.glossary.oilfield.slb.com/displayimage.cfm/1D=22.

[9] Pennington, W.D. (2001). Seismic Time-Lapse Surprise at Teal South: That Little Neighbor Reservoir Is Leaking! The Leading Edge 20 (10): 1172. https://doi.org/10.1190/1.1487249.

[10] Obaje, S.O. (2013). Seismic interpretation of Tomboy Field, Offshore Western Niger Delta, Nigeria. International Journal of Science and Technology. 2(9): 648-660.

[11] Damuth, J.E (1994). Neocene gravity tectonics and depositional processes on the deep Niger Delta continental's margin. Marine and Petroleum Geology 11(3): 320- 345. https://doi.org/10.1016/0264-8172(94)90053-1.

[12] Ajisafe, Y.C. \& Ako, B.D. (2013). 3D seismic attributes for reservoir characterization of "Y" field, Niger Delta, Nigeria. Journal of Applied Geology and Geophysics. 1(2): 23-31. https://doi.org/10.9790/0990-0122331.

[13] Evamy, B. Haremboure, J. \& Kamerling, P. (1978). Hydrocarbon habit of tertiary Niger Delta. American Association of Petroleum Geologist Bulletin. 62: 1-29. https://doi.org/10.1306/C1EA47ED-16C9-11D7-8645000102C1865D.

[14] Doust, H. \& Omatsola, E. (1990). Niger Delta reference. Unpublished Shell Petroleum Company report 1: 201-237.

[15] Etu-Efeotor, J.O. (1997). Fundamentals of Petroleum Geology. Paragraphics: Port-Harcourt, PH.

[16] Whiteman, A.J. (1982). Nigeria: its Petroleum Geology, Resources and Potential. London, Graham and Trotman p. 394. https://doi.org/10.1007/97894-009-7361-9. 